\title{
Inhibition of hesperidin on epithelial to mesenchymal transition of non-small cell lung cancer cells induced by TGF- $\beta 1$
}

\author{
Hai-bin $\mathrm{Yu}^{1}{ }^{1}, \mathrm{LI} \mathrm{Li}^{2}$, Zhou-xin Ren ${ }^{3,4^{*}}$, Jun-ling Shen ${ }^{1}$ \\ ${ }^{1}$ The First Affiliated Hospital of Henan University of TCM, Zhengzhou 450000, China; \\ ${ }^{2}$ The Hospital of Henan Academy Institute of Traditional Chinese Medicine, Henan Zhengzhou 450000, China; \\ ${ }^{3}$ Henan University of Traditional Chinese Medicine, Zhengzhou 450046, China; \\ ${ }^{4}$ Collaborative Innovation Center for Respiratory Disease Diagnosis And Treatment \& Chinese Medicine Development of Henan \\ Province, Zhengzhou 450046, China.
}

\begin{abstract}
Transforming growth factor- $\beta 1$ (TGF- $\beta 1$ ) is a known potent inducer causing epithelial to mesenchymal transition(EMT) in some cancers. The present study was to evaluate the effect of hesperidin on EMT of non-small cell lung cancer (NSCLC) in vitro. In this study, A549 cells, a cellular line of non-small cell lung cancer, were used for evaluation of EMT induced by TGF- $\beta 1$. MTT assay was used to evaluate the effect of hesperidin on cell viability with or without TGF- $\beta 1$ co-culture. At the same time of TGF- $\beta 1$ addition or after cellular morphological change by TGF- $\beta 1$ stimulation, hesperidin was given to cells, respectively. Roundness of cells, E-cadherin, $\alpha$-SMA, Col-I, MMP-9, TIMP- 1 were evaluated EMT by TGF- $\beta 1$ induction and effect of hesperidin on the transition. 40 and $80 \mu \mathrm{M}$ hesperidin showed significant inhibition on cellular viability without TGF- $\beta 1$; coculture with TGF- $\beta 1,40 \mu \mathrm{M}$ hesperidin showed significant inhibition on the viability but not showed significant inhibition after TGF- $\beta 1$ stimulation. Whether co-culture with TGF- $\beta 1$ or addition after TGF- $\beta 1,40 \mu \mathrm{M}$ hesperidin showed inhibitory effect on epithelial to mesenchymal transition and inhibitory effect on extracellular matrix degradation of MMP-9. The above results suggest that hesperidin could be a potential candidate for inhibited migration of non-small cell lung cancer.
\end{abstract}

Key words: Hesperidin, Non-small cell lung cancer, Transforming growth factor- $\beta 1$, Proliferation, Epithelial to mesenchymal transition.

\section{INTRODUCTION}

In the world, Lung cancer with standardized incidence rate (ASIR) is the third major cancer and is the first and most common cause of cancer death. ${ }^{1}$ generally; lung cancers are divided into two major classes, non-small cell lung cancer (NSCLC) and small cell lung cancer (SCLC) and NSCLC accounts for most of all lung cancer cases., ${ }^{2,3}$ Although chemotherapy is applied for treating NSCLC, the effect of treatment is poor due to serious toxicities. ${ }^{4,5}$ Therefore, some studies have paid attention to natural molecules or extracts which made from leaves, seeds, flowers, fruits, barks and roots, expecting to find out ideal anti-NSCLC drugs with non-toxic or low-toxic, cost-effective and physiologically available character. ${ }^{6,7}$

Hesperidin, a natural flavonoid $\left(\mathrm{C}_{28} \mathrm{H}_{34} \mathrm{O}_{15}\right)$ consists of an aglycone (hesperetin) and an attached disaccharide and is abundantly present in oranges and lemons. Hesperidin has wide pharmacological activity, such as anti-inflammatory, analgesic, anti-fungal, antiviral and anti-cancer properties. ${ }^{8}$ As for anti-cancer, studies have shown anti-cancer properties of hesperidin are mainly
Submission Date : 03-05-2016 Revision Date : :31-08-2016 Accepted Date : :09-09-2016

DOI: 10.5530/ijper.50.4.10 Correspondence: Zhou-xin Ren, Henan University of Traditional Chinese Medicine, Zhengzhou 450046, China Phone no: 86-037160254467

E-mail: renzhouxin123@ 126.com

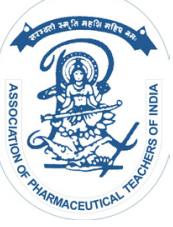

www.ijper.org 
associated with their antioxidant, radical scavenging and anti-inflammatory activities. Hesperidin intervenes in cancer at different stages. Unlike conventional anti-cancer drugs, it inhibits tumor growth by targeting multiple cellular protein targets at the same time, including caspases, Bcl-2 (B-cell lymphoma 2) and $\mathrm{Bax}$ (Bcl-2 associated $\mathrm{X}$ protein) for the induction of apoptosis, and COX-2 (cyclooxygenase-2), and MMP-2 (matrix metalloproteinase-2) for the inhibition of angiogenesis and metastasis. ${ }^{9}$ At present, a study showed that hesperidin could elicit anti-proliferative and apoptotic effects on NSCLC cells through modulating immune response-related pathways that affect apoptosis. ${ }^{9}$ Reviewing the last studies, according to our knowledge, no a study investigated the effect of hesperidin on alveolar epithelial to mesenchymal transition (EMT). However, deaths of NSCLC are mainly attributed to metastasis. ${ }^{10}$ As an early event in tumor metastasis, EMT is critical for the switch of early-stage tumors into invasive malignancies. ${ }^{11}$ As a consequence, deep understanding of effects of hesperidin on EMT is very helpful in evaluating its action of anti-NSCLC, which is our purpose in the study.

\section{MATERIALS AND METHODS}

\section{Cells and culture conditions}

The A549 NSCLC cell line was provided by the Institute of Biochemistry and Cell Biology, Shanghai Institutes for Biological Sciences of Chinese Academy of Sciences (Shanghai, Chine). Cells were cultured in RPMI1640 medium (Beijing Solarbio Science\&Technology Co., Ltd, Chinese, Lot. No. 20131121) supplemented with 10\% fetal bovine serum(FBS, Tian Hang Biological technology Co., Ltd, Chinese Lot No.120509) at 37 $\square$ in a $5 \% \mathrm{CO}_{2}$ incubator. A549 cells were passaged at $80-90 \%$ confluence using $0.25 \%$ trypsin, $1 \mathrm{mM}$ EDTA (Sigma).

\section{Reagents and assay kits}

Recombinant human TGF- $\beta 1$ was purchased from Pepro Tech Ltd (USA). MTT and DMSO were products of Sigma (USA). Soluble ECAD Elisa Kit, human total MMP-9 Elisa kit, $\alpha$-SMA and human TIMP-1 Elisa Kit were purchased from Boster Biological Technology Co., Ltd (Wuhan, China). Human Col-1 Elisa Kit was purchased from Cloud-Clone Corp (Wuhan, China). Mouse anti human $\alpha$-SMA monoclonal antibody and SABC-POD immuno histo-chemistry (mouse IgG) kit were supplied by Boster Biological Technology Co., Ltd (Wuhan, China).

\section{Preparation of hesperidin}

Hesperidin, with $95.3 \%$ purity (ID: 2QHY-PH93), purchased from National Institutes for Food and Drug Control of China, was dissolved in DMSO as a $100 \mathrm{mM}$ stock solution and was filtrated with $0.22 \mu \mathrm{m}$ Millipore Syringe Filters (EMD Millipore Corporation, United States) and stored as aliquots in tightly sealed vials at $-20^{\circ} \mathrm{C}$. Working solutions were prepared by serial dilution of the stock solution with culture medium and were diluted into different doses of hesperidin.

\section{Assay of effect of hesperidin on cell growth with or without TGF- $\beta 1$ stimulation}

For without TGF- $\beta 1$ stimulation, cells were seeded at a density of $3 \times 10^{4} / \mathrm{ml}(0.1 \mathrm{ml} /$ well $)$ in 96-well micro titer plates and allowed to adhere and grow for $24 \mathrm{~h}$. Then, the medium in a well was exchanged into RPMI1640 medium with $10 \%$ fetal bovine serum, supplemented with $0-80 \mu \mathrm{M}$ of hesperidin, respectively. Subsequently cells were incubated for 48 and cell viability was assayed with MTT method.

For with TGF- $\beta 1$ stimulation, after adhering and growing of cells for $24 \mathrm{~h}$, the medium in a well was exchanged into $0.1 \mathrm{ml}$ serum-free RPMI1640 medium and incubated for $8 \mathrm{~h}$ for starvation. Subsequently, cells were treated with RPMI1640 medium supplemented with $10 \%$ fetal bovine serum and $5 \mathrm{ng} / \mathrm{ml}$ TGF- $\beta 1$ as control, or additional 10, 20 and $40 \mu \mathrm{M}$ of hesperidin, respectively. In addition, some cells were treated with RPMI1640 medium supplemented with 10\% fetal bovine serum as normal. Subsequently, all cells were incubated for $48 \mathrm{~h}$. After incubation, cell viability was assayed with MTT method.

\section{Evaluation of effects of hesperidin on EMT induced by TGF- $\beta 1$ \\ Induction of EMT and interference with hesperidin}

Cells were seeded at a density of $5 \times 10^{4} / \mathrm{ml}(0.5 \mathrm{ml} /$ well $)$ in 24-well micro titer plates and allowed to adhere and grow for $24 \mathrm{~h}$. Then the medium in a well was exchanged into $0.5 \mathrm{ml}$ serum-free RPMI1640 medium and incubated for $12 \mathrm{~h}$ for starvation. Subsequently, for assays of co-culture with TGF- $\beta 1$, cells were treated with RPMI1640 medium supplemented with $10 \%$ fetal bovine serum and $5 \mathrm{ng} / \mathrm{ml}$ TGF- $\beta 1$ as control, or additional 10,20 and $40 \mu \mathrm{M}$ of hesperidin, respectively. Furthermore, some cells were treated with RPMI1640 medium supplemented with $10 \%$ fetal bovine serum as normal. Subsequently, all cells were incubated for $48 \mathrm{~h}$. For assays after TGF- $\beta 1$ stimulation, cells were treated with RPMI1640 medium supplemented with $10 \%$ fetal bovine serum and $5 \mathrm{ng} / \mathrm{ml}$ TGF- $\beta 1$ for $12 \mathrm{~h}$. Then, the medium in a well was exchanged into RPMI1640 
medium supplemented with $10 \%$ fetal bovine serum as normal or additional 10, 20 and $40 \mu \mathrm{M}$ hesperidin, respectively. Subsequently, all cells were incubated for $36 \mathrm{~h}$.

\section{Image acquisition and cellular morphometry}

After incubation, all cells were placed in phase contrast microscope (Eclipse MV/TS 100LED-F MV Inverted microscope) and three arbitrary fields of a well in a plate were captured by a digital camera, and saved in a computer. Cellular shape of the images was measured and analyzed in accordance with previous methods. ${ }^{12}$ Adobe Photoshop CS2 (Adobe Systems Inc.) software was used for selecting, depicting shape and segmenting cells in the images. Subsequently, Image Pro Plus 6.0 software (Media Cybernetics) was applied for calculating roundness and radius ratio of the cells and the calculated results were saved in a computer in excel files.

\section{Assay of E-cadherin, Col-I, MMP-9 and TIMP-1 levels}

After image acquisition, all medium was removed into sterile Effendolf tubes and was centrifuged at $1000 \mathrm{~g}$, $4^{\circ} \mathrm{C}$ for $20 \mathrm{~min}$. The supernatant was taken off and stored at $-20^{\circ} \mathrm{C}$. Within 3 days, the E-cadherin and Col-I levels in the supernatant were assayed with enzyme linked immuno sorbent assay kits according to the manufacturer's protocols. Furthermore, total protein value in medium was assayed with BSA method.

\section{Assay of a-SMA expression}

In some 24-well micro titer plates, a round slide was added into a well at the beginning time of culture for cells growing on the slide. Finally, the cells were assayed $\alpha$-SMA with immuno histo-chemistry method as we reported before. ${ }^{13}$ For semi- quantitative measurement of expression of $\alpha$-SMA, Image Pro® Plus 6.0 software (Media Cybernetics, Inc., Bethesda, MD, USA) was run according to instructions. The integrated optical density (IOD) of all the positive staining in each field and area of interest (AOI) was measured. The ratio of Mean Optical density $(\mathrm{MOD}=\mathrm{IOD}$ sum/area) was used to evaluate the expression of the protein.

\section{Statistical analyses}

All the data were expressed as mean \pm standard error of the mean (SEM).The significance of differences between groups was assessed by a one way analysis of variance (ANOVA) using SPSS 16.0. Differences with a p-value of $<0.05$ were considered statistically significant.

\section{RESULTS}

\section{Anti-proliferation effect of hesperidin}

As shown in Figure 1, hesperidin could decreased cellular viability with dose dependency, whether with or without TGF- $\beta 1$ stimulation. $40 \mu \mathrm{M}$ and $80 \mu \mathrm{M}$ hesperidin could significantly decreased cell viability without stimulated by TGF- $\beta 1(\mathrm{P}<0.01) .40 \mu \mathrm{M}$ hesperidin could significantly decreased cell viability with TGF- $\beta 1$ stimulation $(\mathrm{P}<0.01)$, which appeared to inhibitory effect of hesperidin on proliferation of A549 cells stimulated by TGF- $\beta 1$.

The degree of viability of hesperidin-treated was expressed as a percentage of its absorbance value versus the absorbance value of the TGF- $\beta 1 \quad(T G F-\beta 1=0$, Hesperidin=0), then multiplied by 100 . Left figure showed effect of heperidin on cellular proliferation without TGF- $\beta 1$ stimulation and right figure showed that with TGF- $\beta 1$ stimulation.

\section{Effect of hesperidin on cellular morphological change induced by TGF- $\beta 1$}

After 12 h TGF- $\beta 1$ stimulation, most cells showed a decrease in cell-cell contacts and adopted a more elongated shape but most TGF- $\beta 1$-untreated A549 cells showed a pebble-like shape and cell-cell close adhesion (Figure 2). These morphological changes were quantitatively determined by the roundness of the cells. As expected, the roundness value of TGF- $\beta 1$-treated cells was significantly lower than TGF- $\beta 1$-untreated cells $(\mathrm{P}<0.01)$. However, hesperidin could not show the significant effect on the roundness values (Figure 2), suggesting not remarkably effective inhibition for the cellular morphological changes.

\section{Effect of hesperidin on E-cadherin, Col-I, MMP-9 and TIMP-1 levels}

For results of assay of co-culture with TGF- $\beta 1$ and hesperidin, as shown in Figure 3, TGF- $\beta 1$ was showed to significantly increase mensenchymal proteins levels including of collagen I and significantly decrease epithelial protein levels, such as E-cadherin. Hesperidin could significantly inhibit increase of collagen I and significantly inhibit decrease of E-cadherin induced by TGF- $\beta 1$. On the other hand, TGF- $\beta 1$-treated A549 cells secreted more MMP-9, lower TIMP-1, showing imbalance of MMPs/TIMP. Hesperidin could significantly reduced MMP-9 product and increased TIMP-1 production. For results of assay of hesperidin usage after TGF- $\beta 1$ stimulation, other results were similar to those in 

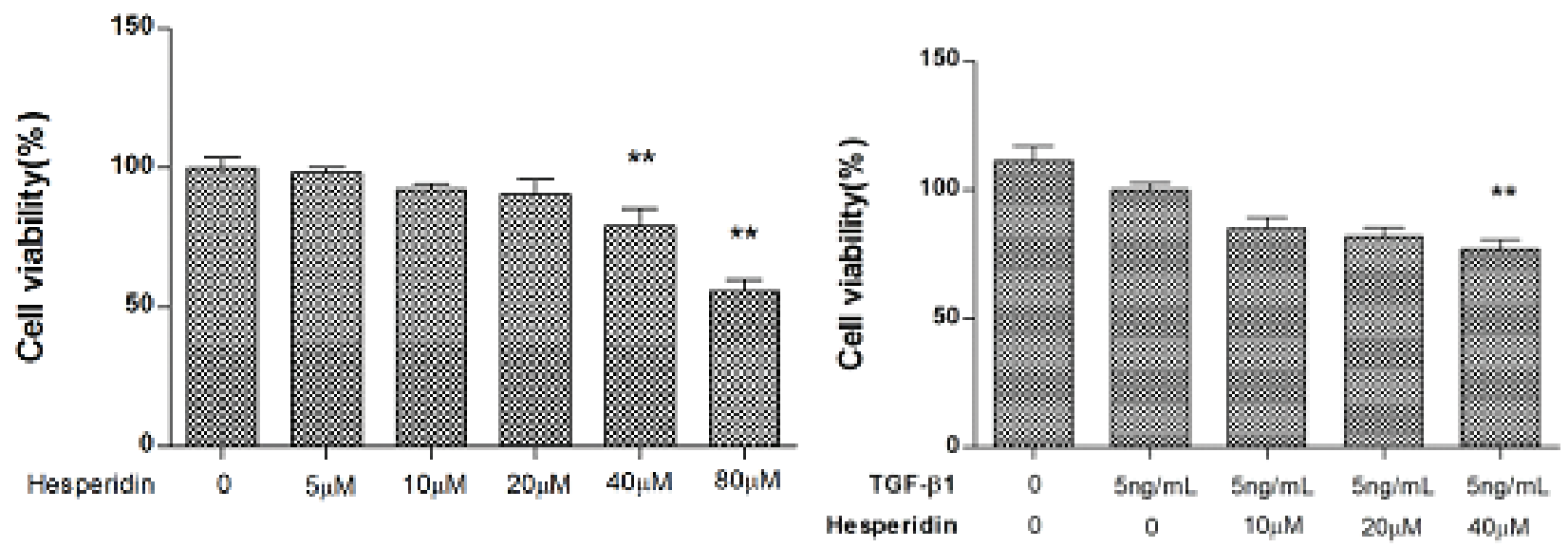

Figure 1: Effect of hesperidin on cell viability of A549 cells.
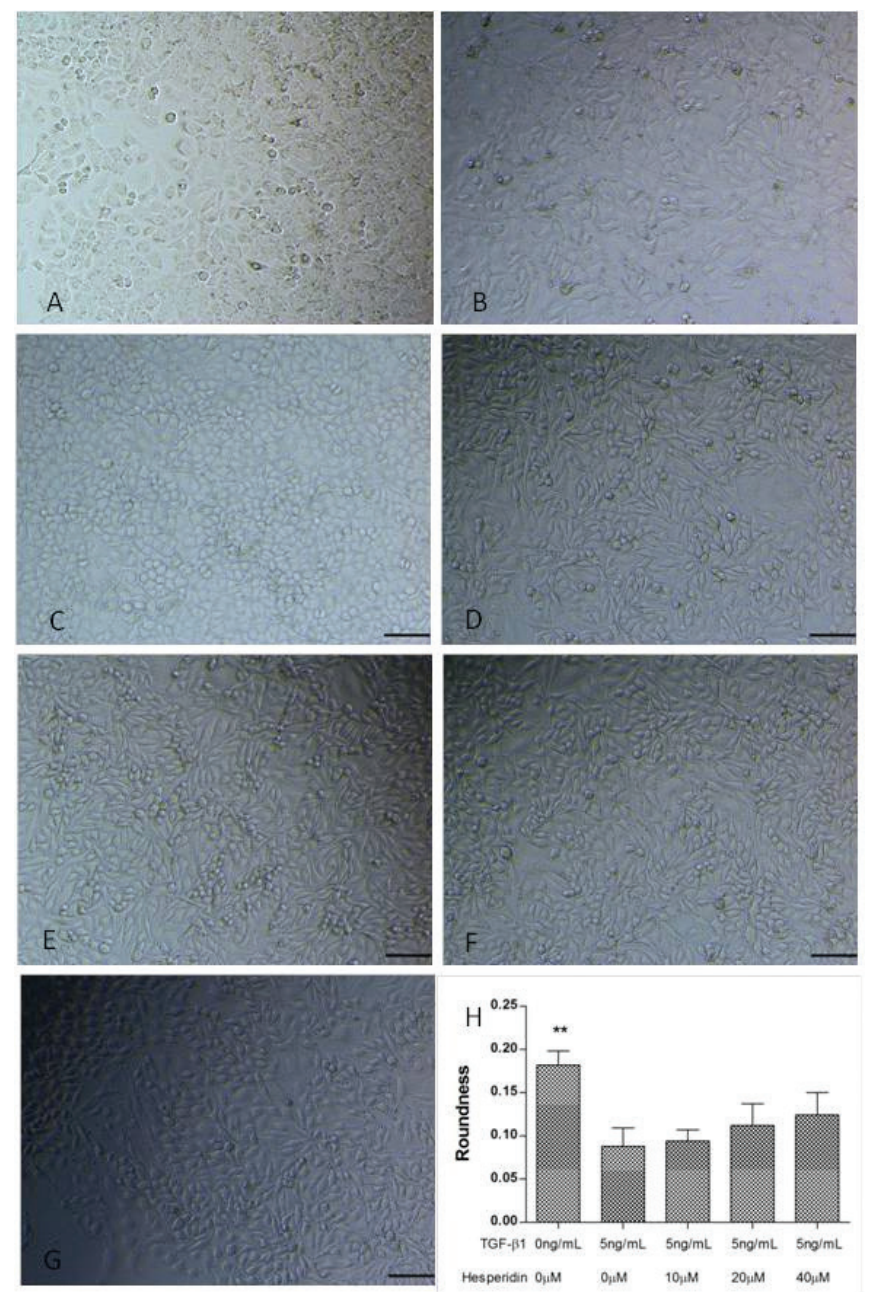

Figure 2: Effect of hesperidin on cell morphological change in TGF- $\beta 1$-induced EMT of A549 cells. (A) shows A549 cells only culture with RPMI1640 medium supplemented with $10 \%$ fetal bovine serum for $12 \mathrm{~h}$; (B) shows A549 cells stimulated by TGF- $\beta 1$ for $12 \mathrm{~h}$; (C) shows A549 cells without co-culturing with TGF- $\beta 1$ and hesperidin, named as control; (D) shows A549 cells with co-culturing with $5.0 \mathrm{ng} / \mathrm{mL}$ TGF- $\beta 1$, named as TGF- $\beta 1$; (E) shows A549 cells with co-culturing with $5.0 \mathrm{ng} / \mathrm{mL}$ TGF- $\beta 1$ and $10 \mu \mathrm{M}$ hesperidin; (F) shows A549 cells with co-culturing with $5.0 \mathrm{ng} / \mathrm{mL}$ TGF- $\beta 1$ and $20 \mu \mathrm{M}$ hesperidin; (G) shows A549 cells with co-culturing with $5.0 \mathrm{ng} / \mathrm{mL}$ TGF- $\beta 1$ and $40 \mu \mathrm{M}$ hesperidin. $(\mathrm{H})$ Roundness assay was calculated using Image Pro Plus 6.0 software. In $\mathrm{C}-\mathrm{H}$ images, magnification was $100 \times$ and bars were $100 \mu \mathrm{m}$. The presented results are the mean $\pm \mathrm{SE}$, sample number $=6$. Comparing to TGF- $\beta 1$ group (TGF- $\beta 1=5 \mathrm{ng} / \mathrm{mL}$, hesperidin $=0$ ), ${ }^{* \star} \mathrm{p}<0.01$. 


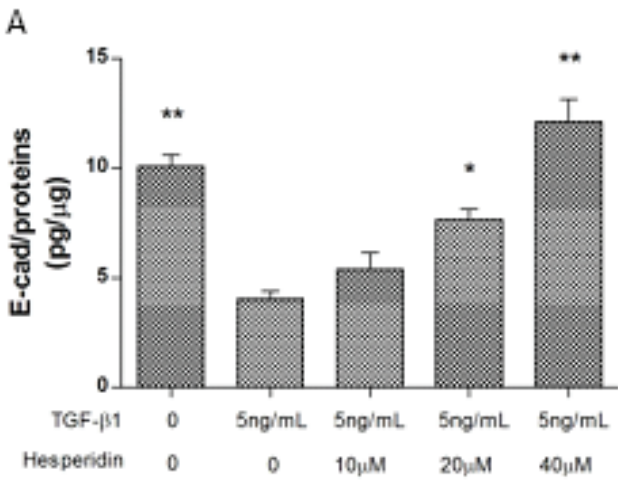

c.

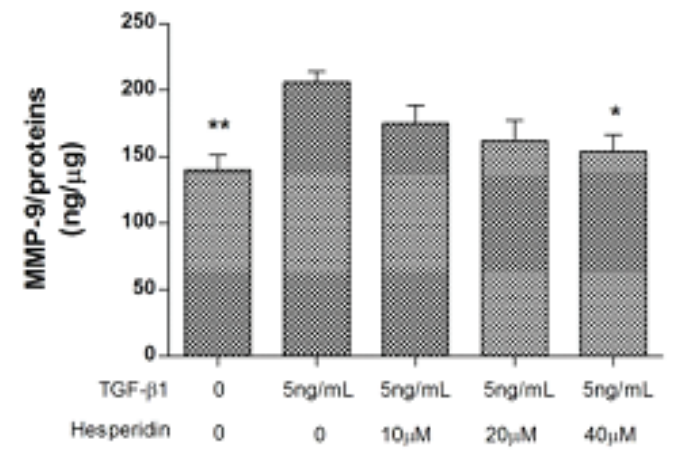

E

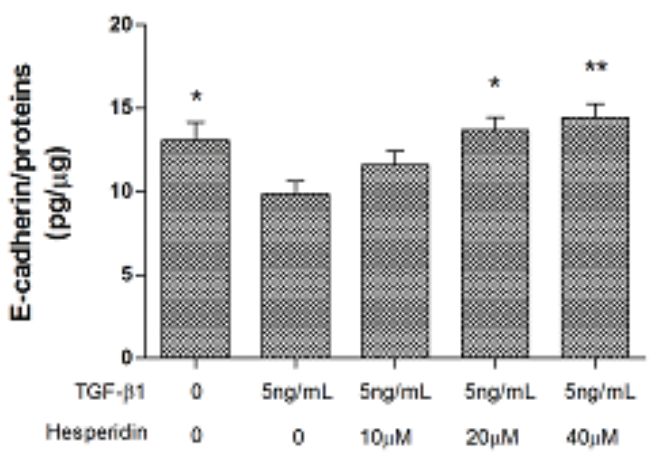

G

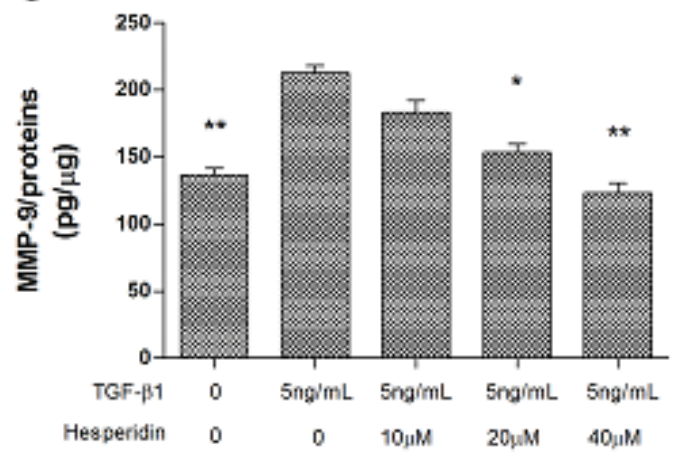

B

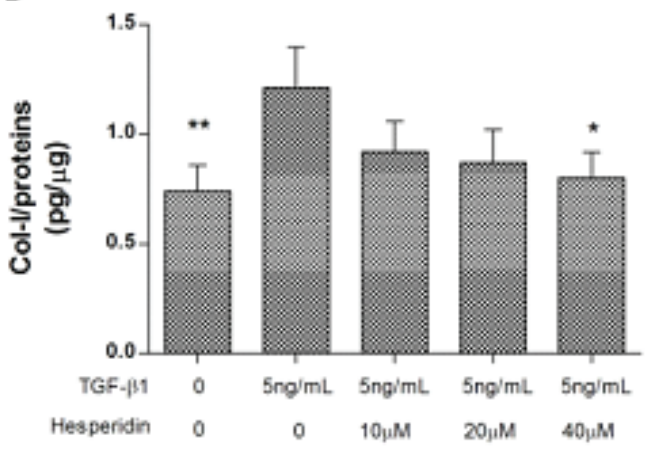

D

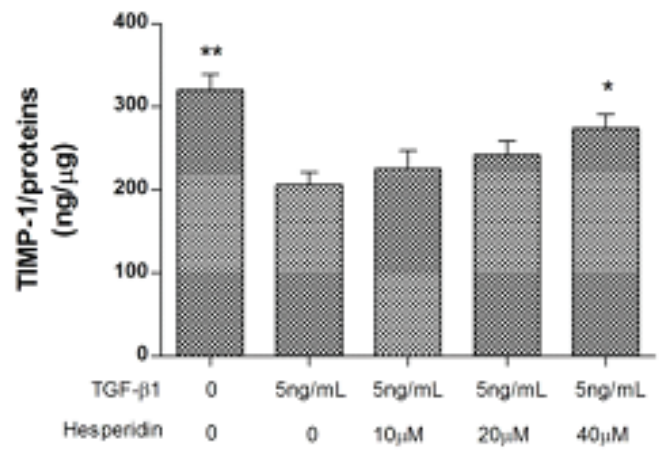

F

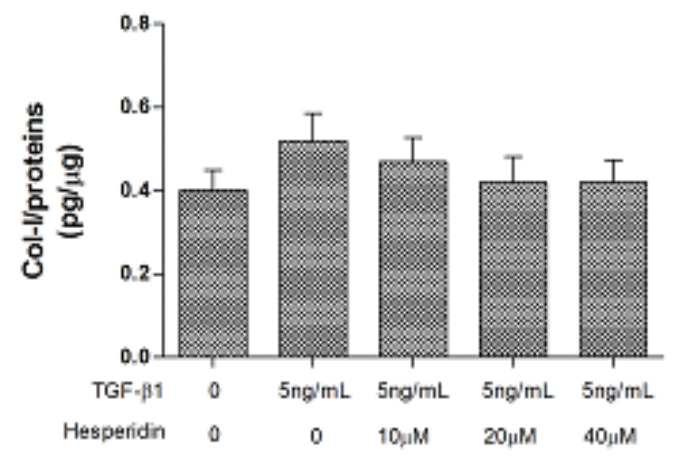

H

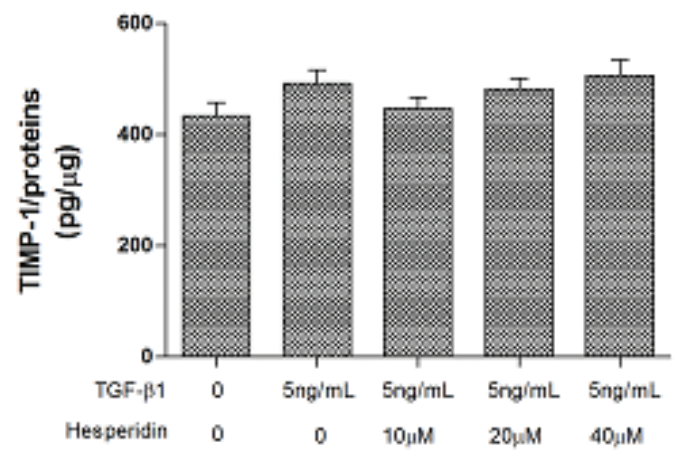

Figure 3: Effect of hesperidin on E-cadherin, Col-I, MMP-9 and TIMP-1 product. The presented results are the mean \pm SE, sample number $=6$. Comparing to TGF- $\beta 1$ group $\left(T G F-\beta 1=5 \mathrm{ng} / \mathrm{mL}\right.$, hesperidin $=0$ ), ${ }^{*} \mathrm{p}<0.05,{ }^{* *} \mathrm{p}<0.01$. A-D figures were the results of the same time of co-culture with TGF- $\beta 1$ and hesperidin and E-H figures were the results of hesperidin usage after $12 \mathrm{~h}$ of TGF- $\beta 1$ stimulation. 

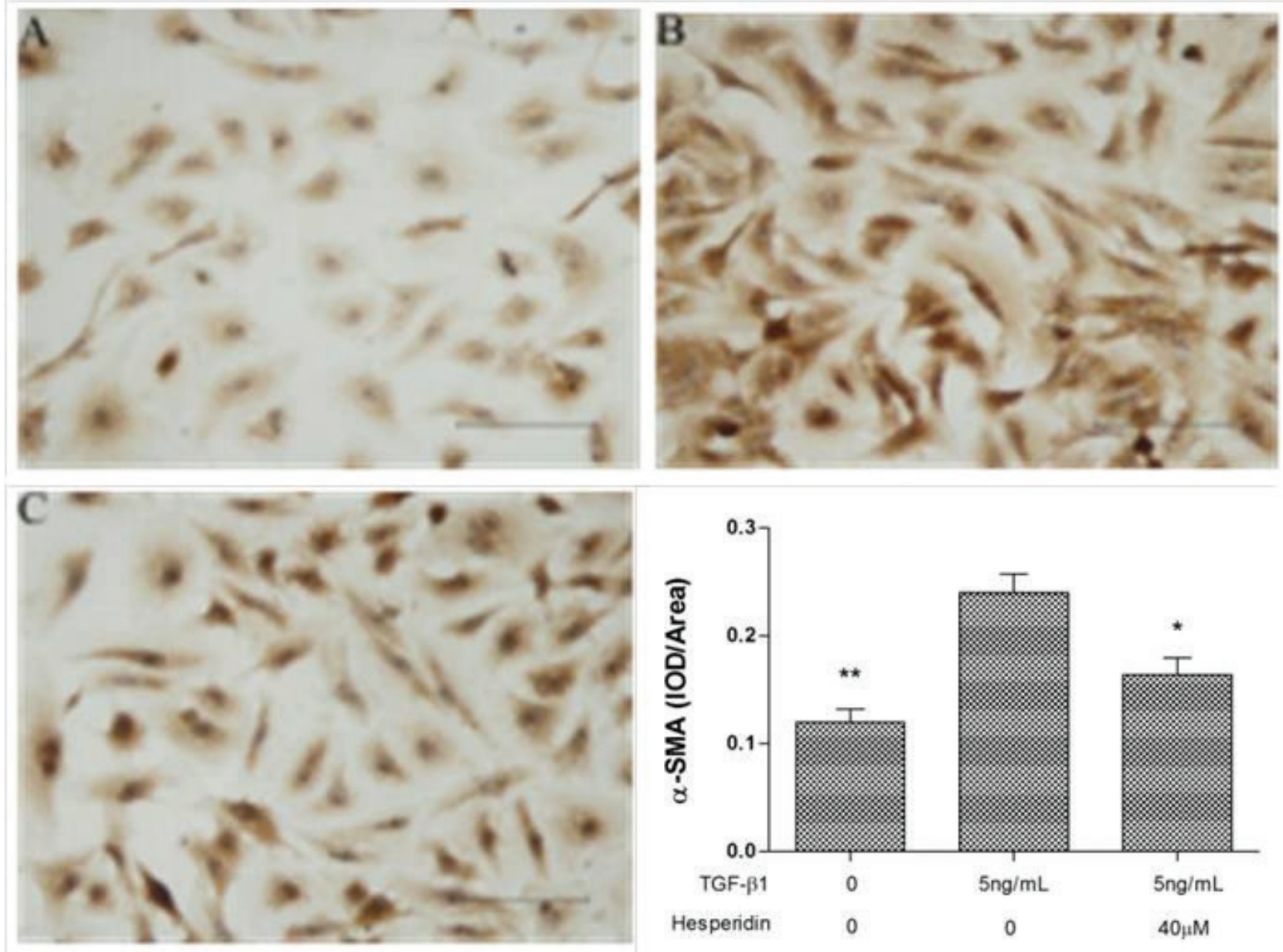

Figure 4: Effect of hesperidin on expression of a-SMA: control (A), TGF- $\beta 1$ (B), and hesperidin (C). Comparing to TGF- $\beta 1$ group (TGF- $\beta 1=5 \mathrm{ng} / \mathrm{mL}$, hesperidin=0), ${ }^{*} p<0.05,{ }^{* *} p<0.01$. In A-D images, magnification was $100 \times$ and bars were $100 \mu \mathrm{m}$.

co-culture except collagen I, showing no significant difference between two groups. The results suggested that hesperidin could inhibit EMT not only in same time of TGF - $\beta 1$ stimulation but also after the time of TGF - $\beta 1$ stimulation.

\section{Effect of hesperidin on expression of a-SMA}

As shown in Figure 4, TGF- $\beta 1$ was showed to significantly increase $\alpha$-SMA protein expression.

\section{DISCUSSION AND CONCLUSION}

In the paper, anti-proliferation activity of hesperidin on A549 cells was evaluated with MT'T assay. In accordance with published papers hesperidin appeared anti-proliferation of cancerous cells under normal culture conditions, ${ }^{9,14}$ and hesperidin, at least $40 \mu \mathrm{M}$, also appeared the similar activity under $5 \mathrm{ng} / \mathrm{mL}$ TGF- $\beta 1$ stimulation. Furthermore, the cells stimulated by $5 \mathrm{ng} / \mathrm{mL}$ TGF- $\beta 1$ showed morphological change from a pebble-like shape and close gaps between cells to a spindle-like shape and wide gaps after $12 \mathrm{~h}$ stimulation, appearing to morphological change of EMT in A549 cells. ${ }^{12,13}$ With increasing of stimulation time, the morphological change was more obvious, with significant decrease of E-cadherin and significant increase of collagen I and $\alpha$-SMA, showing cellular cytoskeleton remodeling. Besides anti-proliferation, $40 \mu \mathrm{M}$ hesperidin, co-culture with TGF- $\beta 1$, showed partly inhibition of the EMT with decrease of collagen I and $\alpha$-SMA and increase of E-cadherin, however, without significant change of cell morphology evaluated by roundness analysis. Similar results were showed in $40 \mu \mathrm{M}$ hesperidin added after $12 \mathrm{~h}$ TGF- $\beta 1$ stimulation. Comparing to $40 \mu \mathrm{M}$ hesperidin, $20 \mu \mathrm{M}$ hesperidin showed lower inhibition of EMT with only significant improvement of E-cadherin, and without significant anti-proliferation. The above results supported our hypothesis that hesperidin might inhibit EMT in NSCLC cells besides anti-proliferation, not only protective effect but also depressing on induced EMT. 
A recent paper showed that hesperetin, a major structure of hesperidin, interfered with ligand-receptor interactions in TGF- $\beta 1$ signaling pathway, ${ }^{15}$ suggesting that hesperidin might have similar effect too. The results in the study from co-culture with TGF- $\beta 1$ supported the hypothesis. On the other hand, the inhibitory effect after $12 \mathrm{~h}$ stimulation of TGF- $\beta 1$ suggested that heperidin might also interfere with signal transduction in cellular plasma or nucleus of TGF- $\beta 1$ signaling pathway.

Consistent with a previous reports, ${ }^{16}$ A549 cells of TGF- $\beta 1$-induced EMT showed significant increase of MMP-9 product and significant decrease or not significant change of TIMP-1, which showed damage of balance of MMP and TIMP expression. Hesperidin could inhibit the changes, out of doubt, relating to its inhibition of EMT. However, according to some published papers, the inhibition on MMP-9 might relate to complex mechanisms, for example, suppressing transcription or expression of MMP-9. ${ }^{17}$ Whether the inhibition on MMP-9 is related to other stimulators and their signal transduction pathways should be explored in the future.

Hesperidin is a low toxic glycoside flavonoid, can be available under low cost, and has anti-cancer activity for NSCLC cells. ${ }^{18}$ Furthermore, it has been found out complex pharmacological actions on anti-cancer, including of antioxidant, radical scavenging, antiinflammatory, inhibitory proliferation, and inhibition of MMP-2 and MMP-9. Different from them, in the study hesperidin was showed inhibitory effect on EMT of NSCLC cells. In NSCLC cells, EMT is attributed to one of key pathways on therapeutic resistance and tumor recurrence, through enhancing the cancer cells to acquire ability of migration, invasion and stem cell like characteristics. ${ }^{19}$ The above results support that hesperidin could be valuable as an agent for anti-NSCLC and the next study will be explored effects of hesperidin on NSCLC animals or patients, alone usage or combined usage with other anti-cancer agents.

\section{ACKNOWLEDGEMENT}

This work was supported by key scientific research project of Colleges and Universities in Henan province [16A360002].

\section{CONFLICT OF INTEREST}

There is no conflict of interest from any of our coauthors.

\section{ABBREVIATION USED}

(NSCLC): Non-small cell lung cancer; (EMT): Epithelial to mesenchymal transition; (IOD): Integrated optical density; (MMP): Matrix metalloproteinase; (TIMPs): Tissue inhibitor metalloproteinases.

\section{REFERENCES}

1. Rafiemanesh H, Mehtarpour M, Khani F, Hesami SM, Shamlou R, Towhidi $\mathrm{F}$, et al. Epidemiology, incidence and mortality of lung cancer and their relationship with the development index in the world. J Thorac Dis. 2016;8(6):1094-102. http://dx.doi.org/10.21037/jtd.2016.03.91; PMid:27293825 PMCid:PMC4886020.

2. Youlden DR, Cramb SM, Baade PD. The International Epidemiology of Lung Cancer: geographical distribution and secular trends. J Thorac Oncol. 2008; 3(8):819-31. http://dx.doi.org/10.1097/JTO.0b013e31818020eb; PMid:18670299.

3. Fan H, Shao ZY, Xiao YY, Xie ZH, Chen W, Xie H, et al. Incidence and survival of non-small cell lung cancer in Shanghai: a population-based cohort study. BMJ Open. 2015;5(12):e009419 http://dx.doi.org/10.1136/ bmjopen-2015-009419; PMid:26700282 PMCid:PMC4691760.

4. Maier A, Peille AL, Vuaroqueaux V, Lahn M. Anti-tumor activity of the TGF- $\beta$ receptor kinase inhibitor galunisertib (LY2157299 monohydrate) in patientderived tumor xenografts. Cell Oncol (Dordr). 2015;38(2):131-44. http://dx.doi. org/10.1007/s13402-014-0210-8; PMid:25573078 PMCid:PMC4412926.

5. Ulivi $P$, Silvestrini R. Role of quantitative and qualitative characteristics of free circulating DNA in the management of patients with non-small cell lung cancer. Cell Oncol (Dordr). 2013;36(6):439-48. http://dx.doi.org/10.1007/ s13402-013-0155-3 ; PMid:24177991.

6. Neal JW, Sequist LV. Exciting new targets in lung cancer therapy: ALK, IGF-1R, HDAC, and Hh. Curr Treat Options Oncol. 2010;11(1-2):36-44. http://dx.doi. org/10.1007/s11864-010-0120-6 PMid:20676809.

7. Molina JR1, Yang P, Cassivi SD, Schild SE, Adjei AA. Non-small cell lung cancer: epidemiology, risk factors, treatment, and survivorship. Mayo Clin Proc. 2008;83(5):584-94 http://dx.doi.org/10.1016/S0025-6196(11)60735-0 http://dx.doi.org/10.4065/83.5.584 PMid:18452692 PMCid:PMC2718421.

8. Rooh BA, Parhiz H, Soltani F, Rezaee R, Iranshahi M. Molecular mechanisms behind the biological effects of hesperidin and hesperetin for the prevention of cancer and cardiovascular diseases. Life Sci. 2015;124:64-74. http:// dx.doi.org/10.1016/j.lfs.2014.12.030 ; PMid:25625242.

9. Birsu CZ, Unlu M, Kiran B, Sinem BE, Baran Y, Cakmakoglu B. Antiproliferative, apoptotic and signal transduction effects of hesperidin in non-small cell lung cancer cells. Cell Oncol (Dordr). 2015;38:195-204. http://dx.doi. org/10.1007/s13402-015-0222-z; PMid:25860498.

10. Gupta GP, Massagué J. Cancer metastasis: building a frame work. Cell. 2006,127(4):679-95. http://dx.doi.org/10.1016/j.cell.2006.11.001; PMid:17110329

11. Kang $\mathrm{Y} 1$, Massagué J. Epithelial-mesenchymal transitions: twist in development and metastasis. Cell. 2004;118(3):277-9. http://dx.doi. org/10.1016/j.cell.2004.07.011; PMid:15294153.

12. Ren ZX, Yu HB, Li JS, Shen JL, Du WS. Suitable parameter choice on quantitative morphology of A549 cell in epithelial-mesenchymal transition. Biosci. Rep. 2015;35(5):e00202. http://dx.doi.org/10.1042/bsr20150070.

13. Ren Zhou-xin, Yu Hai-bin, Li Jian-sheng, Shen Jun-ling, Li Jun-kai, Luo Shan. Inhibitory effect of Panax notoginseng saponins on alveolar epithelial to mesenchymal transition. Zhongguo Zhong Yao Za Zhi. 2015;40(23):4667-71. PMid:27141681.

14. Wang Y, Yu H, Zhang J, Gao J, Ge X, Lou G. Hesperidin inhibits HeLa cell proliferation through apoptosis mediated by endoplasmic reticulum stress pathways and cell cycle arrest. BMC Cancer. 2015;15(1):682. http://dx.doi. org/10.1186/s12885-015-1706-y; PMid:26459308 PMCid:PMC4603924.

15. Yang $Y$, Wolfram J, Shen $H$, Fang $X$, Ferrari M. Hesperetin: an Inhibitor of the Transforming Growth Factor- $\beta$ (TGF- $\beta$ ) Signaling Pathway. Eur J Med Chem. 2012;58:390-5. http://dx.doi.org/10.1016/j.ejmech.2012.10.028; PMid:23153811 PMCid:PMC3513570. 
Yang T, Chen M, Sun T. Simvastatin attenuates TGF-B1-induced epithelialmesenchymal transition in human alveolar epithelial cells. Cell Physiol Biochem. 2013;31(6):863-74. http://dx.doi.org/10.1159/000350104; PMid:23817018.

17. Yeh MH, Kao ST, Hung CM, Liu CJ, Lee KH, Yeh CC. Hesperidin inhibited acetaldehyde-induced matrix metalloproteinase-9 gene expression in human hepatocellular carcinoma cells. Toxicol Lett. 2009;184(3):204-10. http:// dx.doi.org/10.1016/j.toxlet.2008.11.018; PMid:19110045

\section{PICTORIAL ABSTRACT}

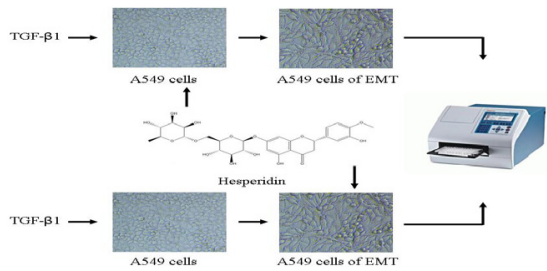

18. Wilson C, Nicholes K, Bustos D, Lin E, Song Q, Stephan JP, et al. Overcoming EMT-associated resistance to anti-cancer drugs via Src/FAK pathway inhibition. Oncotarget. 2014;5(17):7328-41. http://dx.doi.org/10.18632/ oncotarget.2397; PMid:25193862 PMCid:PMC4202126

19. Yuan $\mathrm{X}, \mathrm{Wu} \mathrm{H}, \operatorname{Han} \mathrm{N}, \mathrm{Xu} \mathrm{H}, \mathrm{Chu} Q, \mathrm{Yu} \mathrm{S}$, et al. Notch signaling and EMT in non-small cell lung cancer: biological significance and therapeutic application. J Hematol Oncol. 2014;7(1):87. http://dx.doi.org/10.1186/ s13045-014-0087-z; PMid:25477004 PMCid:PMC4267749.

\section{SUMMARY}

- The study was aimed to evaluate the effect of hesperidin on epithelial to mesenchymal transition induced by TGF- $\beta 1$ in A549 cell, a kind of nonsmall cell lung cancers. Both co administration or after inducing by TGF- $\beta 1$, hesperidin could attenuate key protein molecules changes in the cells. Furthermore, hesperidin could reduce the cell viability with or without TGF- $\beta 1$ co administration.

\section{About Authors}

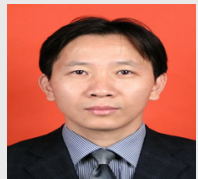

Dr. Hai-bin Yu: Working as Associate Professor in The First Affiliated Hospital of Henan University of TCM. He has 25 years of experience in teaching on pharmacology of traditional Chinese medicinal plants and has published 3 scientific research papers on Science Citation Index and 40 scientific research papers on China National Knowledge Infrastructure (CNKI).

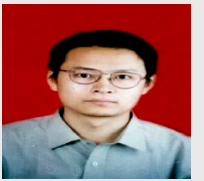

Dr. Zhou-xin Ren: Presently working as Associate Researcher on Collaborative Innovation Center for Respiratory Disease Diagnosis And Treatment \& Chinese Medicine Development of Henan Province and Henan University of Traditional Chinese Medicine. His research areas include pharmacological screening and active principles of traditional Chinese medicinal plants, biotechnological tools and techniques. He has published 2 scientific research papers on Science Citation Index and 50 scientific research papers on China National Knowledge Infrastructure (CNKI). 